Benjamin Edelman

Preliminary Draft

Harvard University

January 14, 2004

ben@edelman.org

http://cyber.law.harvard.edu/edelman

\title{
Earnings and Ratings at Google Answers
}

Most research on Internet transactions has considered these markets as forums to facilitate the sale of physical goods (e.g. Goolsbee [forthcoming], Ellison 2001).

Occasionally the Internet is analyzed as a market for matching workers and firms for an ordinary realworld employment relationship (e.g. Kuhn 2002). But through certain web sites, the Internet can also supplement or even replace in-person employment relationships. This is the result seen in Google Answers, a web-based service that facilitates paid matches between "answerers" (who have answers or research skills) and "askers" (who offer payment for answers to their respective questions).

I analyze all auctions since the inception of the Google Answers service, and I find notable trends in answerer behavior: More experienced answerers provide answers with the characteristics askers most value, receiving higher rankings as a result. Answerers' rate of earnings increases in experience - showing both selection effects and learning on the job. Answerers who focus on particular question categories provide answers of higher quality ("specialization") but earn lower pay per hour (perhaps "lack of versatility"). Answers provided during the business day receive higher payments per hour (a compensating differential for working when outside options are most attractive), but more experienced answerers tend to forego these opportunities.

\section{Methodology \& Data Set}

All data for my analysis comes from the Google Answers web site, http://answers.google.com. I wrote software to extract questions, answers, and profiles 
from the Answers site, forming a database of more than 40,000 questions and answers. With only a few exceptions, ${ }^{1}$ I observe all Google Answers questions and answers posted through November 2003.

For each question asked, I observe the question itself (text, title, substantive categorization within Google Answers' taxonomy), the time at which it was asked, the payment amount offered by asker to answerer, and the asker's username. For answered questions, I observe the time at which the question was answered, the answer itself (including length in characters, and number of included URLs), and the answerer's username. When the asker rated the answer, I observe the rating; when the asker offered a gratuity to the answerer, I observe the amount of the gratuity. I also observe occasional additional discussion of the question and/or answer by actual or would-be answerers, asker, and other visitors to Google Answers; however, I have not used these discussions in my analysis to date.

Google Answers allows an answerer to "lock" a question - obtaining the temporary exclusive right to answer it for the following four to eight hours (depending on question price). However, I do not observe the time when an answerer "locked" a question. $^{2}$

Occasionally an asker is sufficiently dissatisfied with a question that the asker requests a refund from Google. If Google staff deem an answer unacceptably poor under Google Answers rules, the payment to answerer may be reversed. I do not observe the

\footnotetext{
${ }^{1}$ Exceptions include questions for some reason removed by Google (e.g. for profanity or other prohibited content).

${ }^{2}$ Google Answers lock terms have changed somewhat over time. I lack information about the precise form of rules previously in effect and about the dates of transition between rules. However, my sense is that the changes are small and are second-order to the other effects discussed.
} 
disposition of refunded questions, but I do observe the total number of refunded answers submitted by each answerer.

Google Answers receives two kinds of payments for its efforts in facilitating matches between askers and answerers. First, Google Answers receives a \$0.50 listing fee for each question, whether answered or not. Second, Google Answers receives a 25\% commission of answer prices for answered questions. However, Google Answers takes no commission on gratuities.

Google Answers questions may range in price from \$2 to \$200.

\section{Summary Statistics}

To the best of my knowledge, there have been no prior economic analyses of Google Answers. ${ }^{3}$ In Table 1 , I offer selected summary statistics to give a general sense of this unstudied market.

Figures 1 through 7 show the distributions of selected variables. Highlights include the following: More than $78 \%$ questions have value of $\$ 20$ or less, but there are notable clumps of questions at the focal points of $\$ 50, \$ 100, \$ 150$, and $\$ 200$. Answerer earnings include a few extreme outliers, including one answerer who has netted some $\$ 17,000$ from Google Answers for providing more than 900 answers. Answers tend to be provided quickly, with half of answered questions answered within three hours. Ratings are clustered at high values, with ratings below 4 assigned to less than $3 \%$ of rated answers.

\footnotetext{
${ }^{3}$ Librarians at Cornell prepared "Google Meets eBay: What Academic Librarians Can Learn from Alternative Information Providers” (<http://www.dlib.org/dlib/june03/kenney/06kenney.html〉), June 2003. The popular media has also provided assorted coverage of Google Answers.
} 


\section{What Do Askers Value?}

Available data offer two distinct measurements of answer quality as perceived by askers. First, some askers chose to rate the answers they receive, providing numeric assessments of subjective ans wer quality (values of 1 to 5 , with half-points permitted). Second, some askers offer gratuities to their answerers - pure gifts in no way required by Google Answers rules, for which askers receive no direct benefit. ${ }^{4}$

In modeling what characteristics askers value in answers, there are three clear objective measures of answer characteristics likely of interest: answer length in characters, number of URL references in answer, and time in minutes between asking a question and receiving an answer. ${ }^{5}$

Straightforward regressions of rating and of tip on length and/or URL count yield insight as to askers' preferences. In multiple regression specifications, ${ }^{6}$ answer length has statistically significant positive coefficients when predicting rating. This findings suggests that whatever weight askers might place on conciseness, conciseness is not sufficient to overwhelm the risk of incomplete answers. Longer answers also yield both more frequent and larger gratuities.

The effect of URL references is somewhat more ambiguous, though ultimately still positive. In regressions of answer rating, number of URL references takes an

\footnotetext{
${ }^{4}$ The reason why askers provide such gratuities is itself something of a puzzle. Gratuities might have reputational benefits to askers, e.g. increasing the expected total revenue to answers who answer the asker's future questions. But Google Answers' search function does not facilitate searching by asker, i.e. to determine whether a given answer is one who has tipped in the past and might therefore be thought likely to tip in the future. Nonetheless, gratuities aren't mere follies of novice askers; tip amount is positively associated with asker experience $(\mathrm{P}<0.001)$. Agency problems might explain gratuities (e.g. askers are spending others' money), but gratuities are only weakly positively associated with submitting a question during the business day, one possible method of distinguishing business askers from personal askers. ${ }^{5}$ However, it is not obvious from first principles that length and URLs are always positively associated with answer quality: A more concise answer might be preferable to a long answer.

${ }^{6}$ The result holds in the following model specifications: OLS regressions in which rating takes an ordinal value (1 to 5). OLS regressions for which ordinal rating is transformed via the inverse logit function. Logit regressions for which rating is expressed as a Boolean value of 5 versus not -5 . Logit regressions for which rating is a Boolean of at-least-4 versus lower.
} 
insignificantly negative coefficient when answer length is also included as a regressor. But this result seems to reflect the high correlation between answer length and URL references - not surprising since many long answers earn their length via extended quotes from referenced URLs. When answer length is excluded from a regression predicting ratings, URL reference count takes a weakly significant positive coefficient $(\mathrm{P}=0.055)$. When predicting gratuities, URL references have greater power, taking on significantly positive coefficients - suggesting more URLs may not be needed for a good answer (even one worth of a " 5 " rating) but that more are needed for a "great" answer (one receiving a gratuity, especially a large gratuity).

The effect of time in minutes between asking a question and receiving an answer takes varied coefficients, ranging from significantly negative to insignificantly positive, depending on the specification of the model. This suggests that whatever weight answerers place on a timely answer is confounded by covariates, e.g. that a faster answer might tend to be of lower quality ("rushed" rather than "thorough"). See also discussion in Section 5, relating answerer earnings to effort in minutes.

Table s 2 and 3 give the results of the regressions described in this section

\section{Experience and Learning on the Job}

Traditional labor market literature suggests that on-the-job learning plays a significant role in developing worker skills and in facilitating worker productivity. Jovanovic 1996. Analysis of Google Answers confirms the existence of significant onthe-job learning in this market.

Answerers' experience on the job is easily measured: Answerer experience is the number of questions previously answered by each answerer, which I call "contemporary 
answerer experience" or just experience. (This is as distinguished from "ultimate experience" - the number of questions an answerer had answered by the end of data collection.) Although Google Answers does not directly report contemporary answerer experience, i.e. does not explicitly present answerer experience on the Answers web site, I form a variable for contemporary experience by indexing answers reported on Google Answers. In particular, I tabulate prior answers to determine how many questions an answerer had already answered, prior to answering each question at issue, and I call this value the answerer's contemporary experience.

The direct subjective measures of answerer quality - asker rating and asker gratuity, as above - are increasing in answerer experience as measured by questions previously answered. This result holds with P-values $<0.001$ in multiple specifications of the regression, with and without regressors of answer length and URL reference count. See results in Table 4. These results provide prima facie evidence of learning on the job.

While answerer experience contributes in part to the higher ratings of more experienced answers, their higher ratings also reflect a selection effect. Not all answerers remain in Google Answers for the extended period necessary to obtain high experience; many answerers drop out. The "high type" answerers who stay are predictably different from those who leave: Even at the time of their initial answers, high type answers already were earning higher ratings. To isolate this effect, I regress answer rating on contemporary answerer experience as well as an indicator reporting whether answerer experience ultimately exceeded ten (an indicator for high type answerers), and I limit the analysis to each answerer's first ten answers (or fewer, for answerers who dropped out 
before answering ten questions). ${ }^{7}$ I find a statistically significantly positive coefficient on the indicator variable for ultimately answering more than ten questions - meaning that the high type answerers already receive higher ratings in their initial answers. See results in Table 5.

Although selection effects explain a portion of the positive association between experience and ratings, selection effects do not fully negate the hypothesis of learning on the job. For one, note the positive coefficients on contemporary experience in Table 5. In addition, the positive association between experience and ratings holds even among answerers' initial answers, before selection effects can fully take hold. See the positive coefficients on experience when predicting ratings in restricted samples of answers, as shown in the first three columns of Table 6.

Answerers adjust their behavior ("learn") to suit asker preferences for length and URL count. More experienced users tend to submit answers that users view more favorably - a positive coefficient on experience when predicting answer length and when predicting URL count. This result holds across all answerers as well as among new answerers (e.g. regressions restricted to each answerer's first ten answers) and among drop-out answerers (who ultimately answer ten or fewer questions). See results in Table 7. However, as in Table 5, answerer ultimate experience also takes a positive coefficient - suggesting that selection effects also play a role in answerers' evolving answer characteristics.

\section{Hourly Pay as a Function of Experience}

In general it is difficult to measure the amount of time an answerer invests in answering a question. Answerer work time is unobserved even to Google and to the

\footnotetext{
${ }^{7}$ Throughout, regressions were run with other thresholds, yielding comparable results.
} 
asker - for the answerer merely posts an answer into the Google Answers system, thereby completing his responsibilities as an answerer, without explicitly reporting time expended on the task. However, answerer effort can be inferred from elapsed time between when a question is asked and when it is answered. This is so because answerers compete with each other, racing to lock a question (to obtain the exclusive right to answer it) and then promptly preparing answers (typically submitting answers well before the time-limited "lock" expires). The Google Answers "lock" rules encourage these answerer races: Google Answers rules limit an answerer to holding two questions locked at any instant (and social norms and Google guidelines further limit an answerer to a single lock except under special circumstances, e.g. when seeking clarification from an asker ${ }^{8}$ ). Under these circumstances, the delay in minutes between when a question was asked and when it was answered provides a good measure of answerer effort expended in answering a given question.

Of course, even the most self-interested answerer does not merely minimize effort expenditure (e.g. minutes per question); a more sensible objective would be to maximize pay per minute. I therefore form a variable that gives the quotient of answer price (in dollars) divided by minutes of work (formed as described above). I restrict analysis in this section to questions for which an answer was posted within the maximum lock period plus 60 minutes - intended to capture only those questions for which the race condition (described above) was binding and for which the delay between asking and answering a question gives a good measure of answerer effort.

\footnotetext{
${ }^{8}$ See Google Answers: Researcher Guidelines, Locking question 4, "Can I lock more than one question at a time?" 〈http://answers.google.com/answers/researcherguidelines.html\#locktwo>
} 
Even with the restriction to quickly-answered questions, this measure likely overstates answerer effort: If a question is answered (for example) 75 minutes after it was asked, answerer effort must be less than 75 minutes. After all, the answerer is unlikely to have noticed the new question mere seconds after its submission, and the answerer could have stopped to take a phone call or read email midway through his supposed answer effort - yet my analysis treats the answerer as having expended a full 75 minutes of effort. The result of this overstatement of effort is a corresponding understatement of levels of pay per minute. However, I see little reason to fear bias in my estimation of factors affecting pay per minute, for I have no reason to think the bias varies substantially across different kinds of questions or answerers.

Regressing pay per minute on answerer experience, I find a statistically significant positive coefficient. ${ }^{9}$ The magnitude of this coefficient indicates that, all else equal, another question of answerer experience causes an answerer to earn about $\$ 0.0004$ more per minute, or about $\$ 0.02$ more per hour. (The base pay for answerers with no experience is on the order of $\$ 0.127$ per minute, or about $\$ 7.61$ per hour - likely understated, as argued above.)

Answer length and URL count are also found to be positively associated with pay per minute, all significantly. This suggests that the answerers who provide longer answers earn higher pay per minute even after controlling for experience. If longer answers are presumed to require more minutes of effort, ${ }^{10}$ then the positive association between high pay per minute and long answer length means that some answers are

\footnotetext{
${ }^{9}$ This coefficient, like others predicting pay-per-minute, remains significant when regressions are run in logs of pay-per-minute rather than in levels.

${ }^{10}$ The data shows a clear positive association between answer length and minutes worked: The OLS regression of answer length on minutes worked yields a positive coefficient with $\mathrm{P}<0.001$. This effect remains even when controlling for price and rating.
} 
exogenously so much more productive that they can both provide higher quality answers and simultaneously nonetheless earn higher pay per minute. Alternatively, following the suggestion above that longer answers could be less valuable to askers (who might value brevity), the higher pay per minute of long answers might be taken to reflect answerer rushing (e.g. lack of editing that causes longer answers, faster answers, and higher answerer pay per minute).

See results in Table 8.

\section{Specialization}

As answerers become more experienced, they come to specialize in answering particular kinds of questions. To measure specialization, I form variables that report the number of distinct question categories to which an answer has recently provided answers. I group categories into "one digit codes" (“Arts and Entertainment," "Business," "Computers" and so forth) and "two digit codes" (e.g. within Business: "Advertising," "Accounting," "Consulting," and so forth). In particular, I measure the number of distinct one and two-digit codes represented among an answerer's most recent ten answers, reckoned as of the time of each answer submitted. ${ }^{11}$

The number of distinct question categories in which an answerer has participated is decreasing in the answerer's specialization, as the term is usually used, because a more specialized answerer has participated in fewer categories. To give my specialization variables the intuitive interpretation, such that a larger value reflects greater specialization, I transform the specialization variables by subtracting them from their

\footnotetext{
${ }^{11}$ This result also holds when distinct categories are counted among a user's most recent 5 or most recent 20 questions. To avoid bias from each answerers' initial answers (for which prior categories of answers would necessarily be biased downwards merely by the small number of prior answers), analysis only considers answers beyond an answerer's first 10 answers, or first 5 or first 20.
} 
maximum (ten, since analysis considers each answerer's most recent ten answers). I refer to the resulting variable as a specialization index, using the one-digit specialization measure except where otherwise indicated.

I find a statistically significant positive coefficient on the specialization index when predicting experience, implying that on the whole, more experienced answerers are more specialized. ${ }^{12}$ See results in Table 9.

I find statistically significant positive coefficients on the specialization index when predicting ratings and when predicting gratuities. These results indicate that more specialized answerers earn higher ratings and greater gratuities, even when controlling for answerer experience. However, in some specifications, the coefficient on experience ceases to be significant, suggesting that experience may primarily affect ratings through its effect on specialization. See results in Table 10.

I find statistically significant negative coefficients on specialization when predicting pay per hour, implying that more specialized answerers earn less per hour. See the first column of Table 11. This result initially seems counterintuitive, particularly given the finding (above) that more experienced answerers tend to be more specialized. But this finding makes sense due to the relative abundance of answerers relative to questions seeking answers: When an answerer insists on staying within a particular substantive field, the answerer foregoes opportunities in other fields, however lucrative those opportunities might be. This theory is confirmed by the third column of Table 11,

\footnotetext{
12 Analysis is limited to each answerer's first 100 answers. Those few answerers who have answered more than 100 questions defy the relationship described here. For them, the limited pool of questions available likely requires that they answer a broader swath of questions, from a more varied set of categories, in order to have answered so many questions.
} 
finding a negative relationship between specialization and average price of answered questions.

This analysis suggests that answerer "specialization" may not be an unambiguously positive characteristic. For question askers, specialization is associated with favorable ratings, per above, making specialization a positive attribute (intuitively: "my question was answered by an expert in this field"). But from answerers' perspective, "specialization" could be recast as "lack of versatility" - an inability or disinclination to answer whatever questions arise, and therefore a negative characteristic when predicting earnings.

With this understanding of answer quality vis-à-vis answerer specialization, Google could improve answer quality by requiring answerers to stay within their onedigit or two-digit category or categories of expertise. Such a rule would prohibit answerers from straying to give answers that may be profitable to answerers, but that on average are less well-received.

\section{Compensating Differentials: Day of Week, Hour of Day}

From the perspective of answerers, Google Answers at any instant provides a menu of opportunities - questions that could be answered to earn the payments offered by askers. Availability on the menu depends both on what questions have been sub mitted recently and on what questions have already been answered. Because questions tend to be submitted at certain times of day and on certain days of the week, and because answerers are not always on hand to immediately answer questions submitted, Google Answers opportunities vary somewhat over the course of each week. Compensating 
differentials arise from systematic imbalances between the dates and times at which questions tend to be asked versus when they tend to be answered.

Summary statistics indic ate several notable day-of-week effects. Sundays have the shortest average lag between when questions are asked and when answered, and (after Saturday) both the second-lowest wages per minute of questions answered and the second-fewest number of questions asked - all suggesting a relative lack of Sunday work for answerers, relative to the number of answerers available. Mondays have the highest pay per minute, the second-highest number of questions asked, and the second-longest delay until answer - suggesting a relative lack of Monday answerers compared with the number of questions asked. These results are consistent with question askers who tend to follow the business week, and with answerers who tend to participate on weekends. ${ }^{13}$ See details in Table 12.

Regressions of pay per minute on dummy variables for Sunday and Monday bear out the day-of-week effects described above: The Sunday variable takes a statistically significant negative coefficient when predicting pay per minute; Monday, positive. See details in Table 13.

Summary statistics indicate that questions and answers also differ dramatically according to the time of day when posted. There are numerous notable and statistically significant effects, most of them intuitive : For example, questions posted at 8, 9, and 10 pm have the fastest answers, while questions posted between $2 \mathrm{am}$ and $7 \mathrm{am}$ have the

\footnotetext{
13 The Monday results are also consistent with the author's introspection, that Mondays are generally the busiest day of his week, perhaps due to pent-up tasks accumulated over the preceding weekend. The relative lack of Monday answerers might reflect that answerers perceive similar time pressures on Mondays.
} 
slowest answers. ${ }^{14}$ Although both asking and answering of questions are less frequent during the night, disproportionately fewer answerers seem to be available in the middle of the night relative to the number of questions asked during this period.

Answerers earn a compensating differential for answering questions during the business day. I define the business day as Monday through Friday between 7am and 3pm Pacific time. ${ }^{15}$ A significant positive coefficient results from regressing pay per minute on an indicator reporting whether a question was answered during the business day. That coefficient remains positive even after controlling for answerer experience. However, the coefficient on interaction of business day and experience is insignificant, suggesting that the compensating differential for answering questions during the business day is no larger for experienced answerers. See Table 14.

These results indicate that answerers receive a compensating differential - higher pay per minute - in exchange for answering questions during the business day. Such compensation makes sense in equilibrium because answerers have more favorable outside employment options during the business day. The net effect is likely larger than Table 14 indicates because business day answers are also more than twice as likely to receive a gratuity (15\% rather than 7\%) and therefore receive larger tips in expectation $(\$ 1.34$ in expectation, versus $\$ 0.61$ ); experienced answerers are likely to know of the interaction between business day answers and gratuities, since gratuities are publicly posted.

The correct interpretation of these differential values of answerer pay per minute seems to be as compensating differentials rather than as arbitrage opportunities. To

\footnotetext{
${ }^{14}$ All times are Pacific time.

${ }^{15}$ I lack information about answerers' home time zones. This interval reflects my attempt to produce a single representative business day, based on my understanding that most answerers are based in North America and therefore tend to follow its time zones and business day.
} 
obtain the higher pay per minute, answerers must modify their behavior by answering questions during the business day, likely a costly change for many answerers (e.g. those with other business day obligations). Indeed, more experienced answerers do not tend to take advantage of the compensating differentials. Table 15 indicates that more experienced answerers are significantly less likely to answer questions during the business day, while more experienced answers are not significantly more likely than other answerers to answer questions on Monday and are not significantly less likely to answer on Sundays. These findings are consistent intuition that the "graveyard shift" is undesirable in traditional industries - even with whatever additional pay it may offer.

\section{Extensions and Future Work}

I like the prospect of studying purely electronic labor markets - wherein the entire employment relationship takes place online. Google Answers provides one obvious such example, but my further work here would be much aided by even fuller data. For example, it would be helpful to know answerers' education and geographic location, both of which would begin to speak to outside employment options. I believe Google received this data from answerer membership applications (which include resumes and other personal information), but the data may not be in organized, machine-readable form. In any event, I have so far been fruitless in my inquiries to contacts at Google.

I know I will need more focus to make for a compelling journal article; as it stands, my draft offers a laundry list of questions the existing data can answer, but I so far lack any single question or unifying theme. I could readily make my analysis

proscriptive rather than descriptive - telling Google what rules would most improve answer quality, and telling answerers what behaviors would most improve pay per 
minute - making for a paper of substantial interest to the corresponding audiences, though perhaps still of somewhat lesser interest to economists. 


\section{References}

Ellison, Glenn and Sara Fisher Ellison. "Search, Obfuscation, and Price Elasticities on the Internet." June 2001.

Goolsbee, Austan, and Judy Chevalier. 'Price Competition Online: Amazon versus Barnes and Noble." Forthcoming, Quantitative Marketing and Economics.

Jovanovic, Boyan, and Yaw Nyarko. "Stepping Stone Mobility." NBER Working Paper 5651. July 1996.

Kuhn, Peter. "Internet Job Search and Unemployment Durations." IZA Discussion Paper 613. October 2002. 


\section{Tables and Figures}

\section{Table 1: Summary Statistics}

Google Answers began

April 2002

Data ends

November 2003

Number of questions asked to date

43,262

Number of questions answered to date

Number of distinct question askers

24,724

Number of distinct question answerers

Average dollar value of answered questions

$\$ 18.91$

Maximum dollar value of answered question

$\$ 200.00$

Minimum dollar value of answered questions

$\$ 2.00$

Total revenues to answerers from all answered questions

$\$ 344,495.46$

Total revenues to Google from all questions

$\$ 136,012.82$

Max questions answered by a single answerer

Max dollar value of answers by a single answerer

$\$ 17,495.60$

Proportion of answered questions receiving gratuities

\section{Figure 1: Histogram of Question Submission Dates}

Among Answered Questions

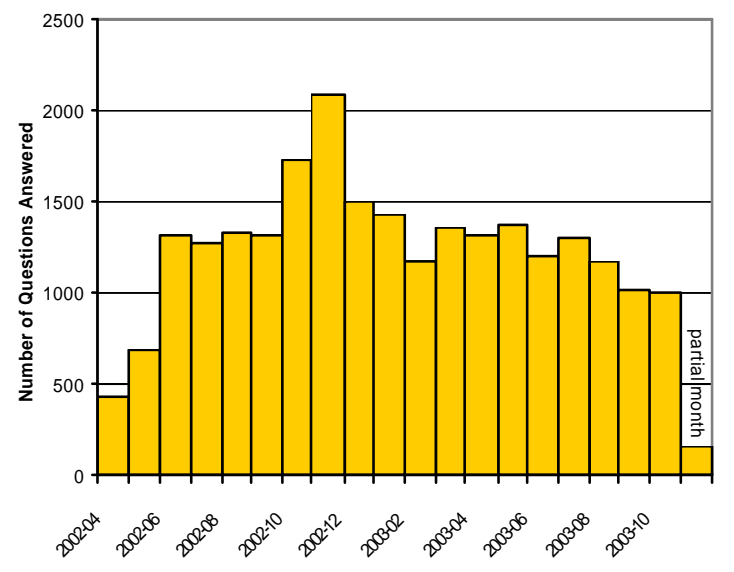


Figure 2: Histogram of Question Prices

Among answered questions

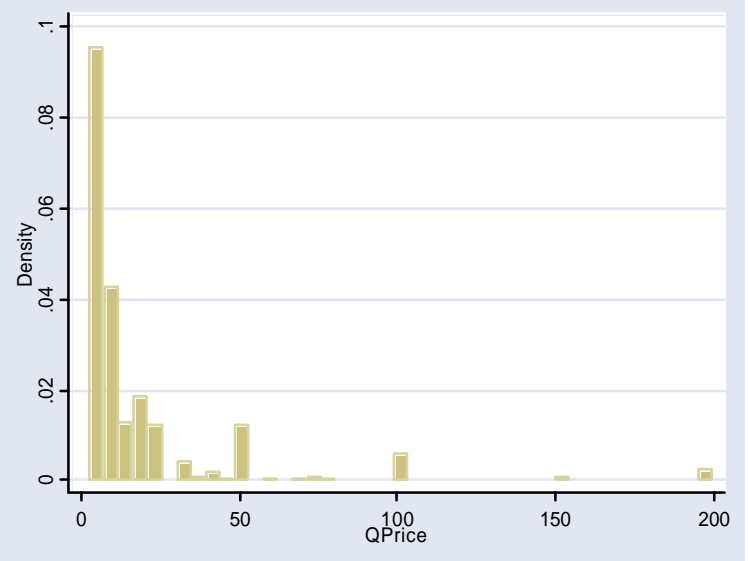

Figure 3: Histogram of Answerer Earnings

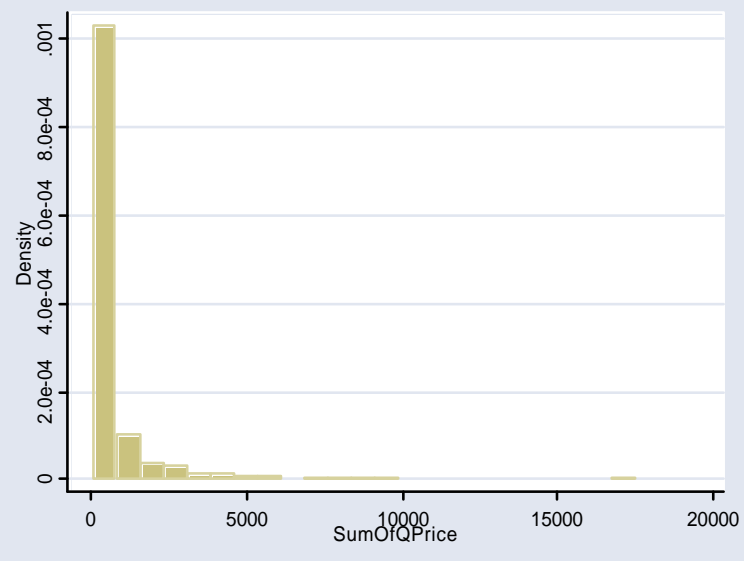

Figure 4: Histogram of Questions Answered Per Answerer

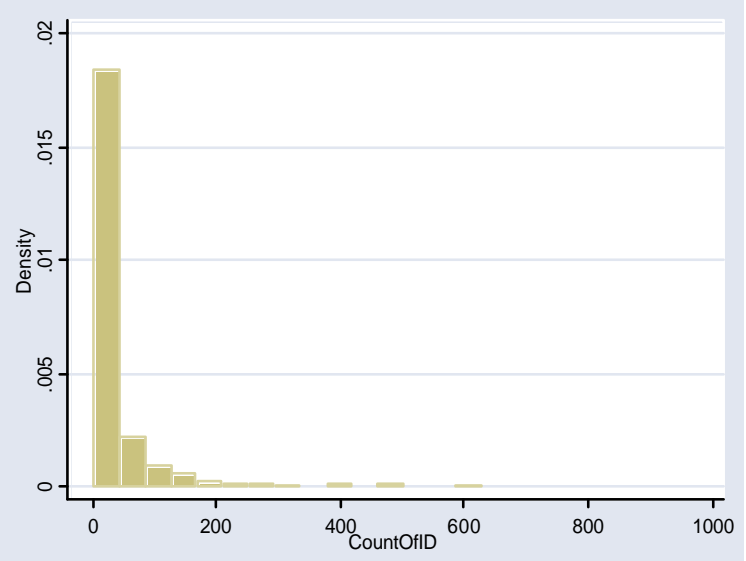


Figure 5: Histogram of Average Earnings Per Question, by Answerer

This histogram plots the density of answerers according to their average earnings per question answered.

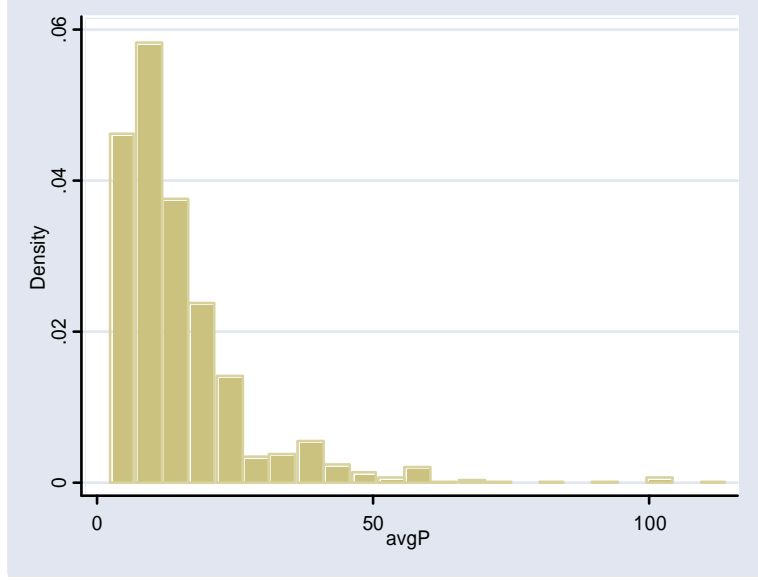

\section{Figures 6a,b,c: Histograms of Average Time to Answer}

These histograms plot the time in minutes between question submission and answer, for questions that are answered. The first histogram gives a full plot of the entire distribution, while the second and third reduce the $\mathrm{X}$ axis range to focus on questions answered quickly. The $\mathrm{x}$ axis is measured in minutes; 1440 minutes equals one day.
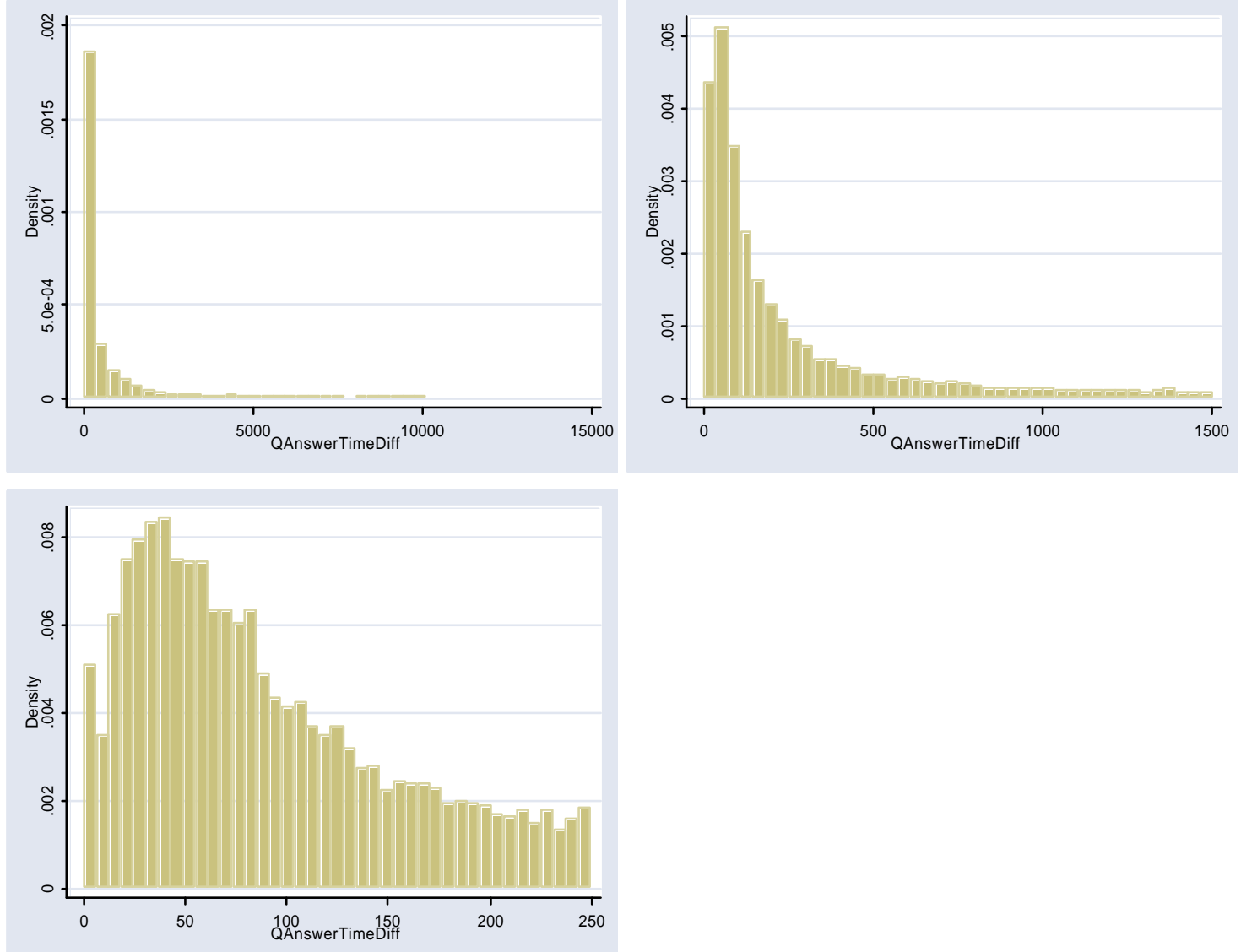
Figure 7: Answer Ratings

Among rated, answered questions.

\begin{tabular}{rrr}
\hline Rating & \multicolumn{1}{l}{ Count } & Frequency \\
5 & 343 & 0.014 \\
4.5 & 16183 & 0.666 \\
4 & 7036 & 0.290 \\
3.5 & 483 & 0.020 \\
3 & 138 & 0.006 \\
2.5 & 17 & 0.001 \\
2 & 12 & 0.000 \\
1.5 & 4 & 0.000 \\
1 & 9 & 0.000 \\
\hline
\end{tabular}

Table 2: What Askers Value: Length, URL References

\begin{tabular}{|c|c|c|c|c|c|c|}
\hline & (1) & (2) & (3) & (4) & (5) & (6) \\
\hline & Rating & Rating & Rating & $\begin{array}{l}\text { Rescaled } \\
\text { Rating }\end{array}$ & $\begin{array}{l}\text { Rescaled } \\
\text { Rating }\end{array}$ & $\begin{array}{l}\text { Rescaled } \\
\text { Rating }\end{array}$ \\
\hline Ans Length & $\begin{array}{r}3.49 E-06 \\
(1.038 e-06)^{\star *}\end{array}$ & & $\begin{array}{r}4.61 \mathrm{E}-06 \\
(1.263 \mathrm{e}-06)^{* *}\end{array}$ & $\begin{array}{r}8.35 \mathrm{E}-07 \\
(2.122 \mathrm{e}-07)^{\star *}\end{array}$ & & $\begin{array}{r}1.02 \mathrm{E}-06 \\
(2.582 \mathrm{e}-07)^{\star *}\end{array}$ \\
\hline Num URLs & & $\begin{array}{r}3.79 \mathrm{E}-04 \\
(6.04 \mathrm{E}-04)\end{array}$ & $\begin{array}{r}-1.15 \mathrm{E}-03 \\
(7.34 \mathrm{E}-04)\end{array}$ & & $\begin{array}{r}1.53 \mathrm{E}-04 \\
(1.23 \mathrm{E}-04)\end{array}$ & $\begin{array}{r}-1.83 E-04 \\
(1.50 E-04)\end{array}$ \\
\hline Constant & $\begin{array}{r}4.543 \\
(0.008)^{\star *}\end{array}$ & $\begin{array}{r}4.555 \\
(0.008)^{\star *}\end{array}$ & $\begin{array}{r}4.546 \\
(0.008)^{\star *}\end{array}$ & $\begin{array}{r}-0.765 \\
(0.002)^{\star \star}\end{array}$ & $\begin{array}{r}-0.762 \\
(0.002)^{\star *}\end{array}$ & $\begin{array}{r}-0.764 \\
(0.002)^{\star \star}\end{array}$ \\
\hline & (7) & (8) & (9) & (10) & (11) & (12) \\
\hline & $\begin{array}{l}\text { logit: } \\
\text { Rating = } 4\end{array}$ & $\begin{array}{l}\text { logit: } \\
\text { Rating }=4\end{array}$ & $\begin{array}{l}\text { logit: } \\
\text { Rating }=4\end{array}$ & Gratuity & Gratuity & Gratuity \\
\hline Ans Length & $\begin{array}{r}2.02 E-05 \\
(6.572 e-06)^{\star \star}\end{array}$ & & $\begin{array}{r}2.14 \mathrm{E}-05 \\
(8.644 \mathrm{e}-06)^{*}\end{array}$ & $\begin{array}{r}1.20 \mathrm{E}-04 \\
(5.829 \mathrm{e}-06)^{\star *}\end{array}$ & & $\begin{array}{r}1.05 E-04 \\
(6.934 e-06)^{\star *}\end{array}$ \\
\hline Num URLs & & $\begin{array}{r}5.78 \mathrm{E}-03 \\
(3.01 \mathrm{E}-03)\end{array}$ & $\begin{array}{c}-7.39 E-04 \\
(3.63 E-03)\end{array}$ & & $\begin{array}{r}4.70 \mathrm{E}-02 \\
(3.260 \mathrm{e}-03)^{* *}\end{array}$ & $\begin{array}{r}1.53 \mathrm{E}-02 \\
(3.861 \mathrm{e}-03)^{* *}\end{array}$ \\
\hline Constant & $\begin{array}{r}2.747 \\
(0.038)^{\star \star}\end{array}$ & $\begin{array}{r}2.79 \\
(0.035)^{\star \star}\end{array}$ & $\begin{array}{r}2.747 \\
(0.038)^{\star \star}\end{array}$ & $\begin{array}{r}0.831 \\
(0.048)^{\star \star}\end{array}$ & $\begin{array}{r}1.011 \\
(0.048)^{\star *}\end{array}$ & $\begin{array}{r}0.782 \\
(0.050)^{\star \star}\end{array}$ \\
\hline
\end{tabular}


Table 3: What Askers Value: Time

\begin{tabular}{|c|c|c|c|c|}
\hline & (1) & (2) & (3) & (4) \\
\hline & Rescaled & Rescaled & Rescaled & logit: \\
\hline & Rating & Rating & Rating & Rating $=4$ \\
\hline \multirow[t]{2}{*}{ Answer Time Lapse } & $-5.50 E-07$ & $-9.75 E-07$ & $-1.07 E-06$ & $-3.40 \mathrm{E}-06$ \\
\hline & $(2.125 e-07)^{\star \star}$ & $(2.804 e-07)^{\star *}$ & $(2.814 \mathrm{e}-07)^{\star *}$ & $(1.21 E-05)$ \\
\hline \multirow{2}{*}{ Answer Time Lapse ${ }^{\wedge} 2$} & & $2.48 \mathrm{E}-12$ & 2.67E-12 & $1.82 \mathrm{E}-10$ \\
\hline & & $(1.066 \mathrm{e}-12)^{*}$ & $(1.067 e-12)^{*}$ & $(3.49 E-10)$ \\
\hline \multirow[t]{2}{*}{ Answer Length } & & & 1.06E-06 & 2.14E-05 \\
\hline & & & $(2.584 e-07)^{\star \star}$ & $(8.667 e-06)^{\star}$ \\
\hline \multirow[t]{2}{*}{ Num URLs } & & & $-1.63 E-04$ & $-7.64 \mathrm{E}-04$ \\
\hline & & & $(1.50 \mathrm{E}-04)$ & (3.63E -03) \\
\hline \multirow[t]{2}{*}{ Constant } & -0.76 & -0.76 & -0.763 & 2.746 \\
\hline & $(0.001)^{\star *}$ & $(0.001)^{\star *}$ & $(0.002)^{* *}$ & $(0.040)^{\star *}$ \\
\hline
\end{tabular}

Table 4: Change in Ratings with Experience

\begin{tabular}{|c|c|c|c|c|}
\hline & (1) & (2) & (3) & (4) \\
\hline & Rating & Rescaled Rating & logit: Rating = 4 & logit: Rating=5 \\
\hline \multirow[t]{2}{*}{ Experience } & $5.88 \mathrm{E}-04$ & 1.08E-04 & 2.23E -03 & 1.13E-03 \\
\hline & $(3.887 e-05)^{\star *}$ & $(7.959 \mathrm{e}-06)^{\star \star}$ & $(2.365 e-04)^{\star \star}$ & $(7.960 e-05)^{\star *}$ \\
\hline \multirow[t]{4}{*}{ Constant } & 4.478 & -0.776 & 2.587 & -0.438 \\
\hline & $(0.008)^{* *}$ & $(0.002)^{* *}$ & $(0.035)^{\star *}$ & $(0.017)^{\star *}$ \\
\hline & (5) & (6) & (7) & (8) \\
\hline & Rating & Rescaled Rating & logit: Rating = 4 & logit: Rating $=5$ \\
\hline \multirow[t]{2}{*}{ Experience } & 5.88E-04 & 1.08E-04 & 2.19E-03 & 1.14E-03 \\
\hline & $(3.893 e-05)^{\star \star}$ & $(7.970 e-06)^{\star \star}$ & $(2.358 e-04)^{\star *}$ & $(7.980 e-05)^{\star \star}$ \\
\hline \multirow[t]{2}{*}{ Answer Length } & 4.46E-06 & 9.87E-07 & 1.88E-05 & 1.05E-05 \\
\hline & $(1.253 e-06)^{* *}$ & $(2.566 e-07)^{\star *}$ & $(8.459 e-06)^{*}$ & $(2.927 e-06)^{\star *}$ \\
\hline \multirow[t]{2}{*}{ Num URLs } & $-1.63 E-03$ & $-2.72 E-04$ & $-1.82 E-03$ & $-6.33 E-03$ \\
\hline & $(7.294 e-04)^{\star}$ & $(1.49 E-04)$ & (3.44E-03) & $(1.519 e-03)^{\star \star}$ \\
\hline \multirow[t]{2}{*}{ Constant } & 4.47 & -0.778 & 2.526 & -0.439 \\
\hline & $(0.010)^{\star *}$ & $(0.002)^{\star *}$ & $(0.043)^{\star \star}$ & $(0.019)^{\star *}$ \\
\hline
\end{tabular}

Table 5: Change in Ratings with Experience: Selection Effects

\begin{tabular}{|c|c|c|c|}
\hline & (1) & (2) & (3) \\
\hline & Rating & Rescaled & logit: \\
\hline \multirow{2}{*}{ Contemp. Experience } & $201 E-02$ & $\begin{array}{l}\text { Rating } \\
421 \mathrm{E}-03\end{array}$ & $\begin{array}{r}\text { Rating }=4 \\
262 \mathrm{E}-02\end{array}$ \\
\hline & $(6.822 \mathrm{e}-03)^{\star \star}$ & $(1.509 e-03)^{\star *}$ & $(1.92 \mathrm{E}-02)$ \\
\hline \multirow[t]{2}{*}{ Future Exper $=10$} & 0.205 & 0.051 & 0.316 \\
\hline & $(0.081)^{\star}$ & $(0.018)^{\star \star}$ & $(0.192)$ \\
\hline \multirow[t]{2}{*}{ Constant } & 4.085 & -0.864 & 1.947 \\
\hline & $(0.074)^{\star \star}$ & $(0.016)^{\star \star}$ & $(0.169)^{\star \star}$ \\
\hline
\end{tabular}


Table 6: Change in Ratings with Experience: Learning

Among each answerer's first ten answers

\begin{tabular}{|c|c|c|c|}
\hline & (1) & (2) & (3) \\
\hline & Rating & Rescaled & logit: \\
\hline & & Rating & Rating $=4$ \\
\hline \multirow[t]{2}{*}{ Experience } & $2.58 \mathrm{E}-02$ & 5.64E-03 & 3.68E-02 \\
\hline & $(6.444 e-03)^{\star *}$ & $(1.426 \mathrm{e}-03)^{\star \star}$ & $(1.797 e-02)^{\star}$ \\
\hline \multirow[t]{2}{*}{ Constant } & 4.249 & -0.824 & 2.189 \\
\hline & $(0.035)^{* *}$ & $(0.008)^{\star *}$ & $(0.091)^{\star \star}$ \\
\hline
\end{tabular}

Among answers from answerers who dropped out after $=10$ answers

\begin{tabular}{|c|c|c|c|}
\hline & (4) & (5) & (6) \\
\hline & Rating & Rescaled & logit: \\
\hline & & Rating & Rating $=4$ \\
\hline \multirow[t]{2}{*}{ Experience } & $6.71 \mathrm{E}-02$ & 1.49E-02 & 6.20E-02 \\
\hline & $(2.085 e-02)^{\star \star}$ & $(4.857 e-03)^{* *}$ & $(0.05142)$ \\
\hline \multirow[t]{2}{*}{ Constant } & 4.15 & -0.853 & 2.062 \\
\hline & $(0.068)^{\star \star}$ & $(0.016)^{\star \star}$ & $(0.149)^{\star *}$ \\
\hline
\end{tabular}

Among answers from answerers who persisted for $>10$ answers

\begin{tabular}{lrlr} 
& \multicolumn{1}{l}{$(7)$} & $(8)$ & \multicolumn{1}{l}{$(9)$} \\
& \multicolumn{1}{l}{ Rating } & \multicolumn{1}{l}{ Rescaled } & \multicolumn{1}{l}{ logit: } \\
Experience & $5.56 \mathrm{E}-04$ & Rating & \multicolumn{1}{l}{ Rating $=4$} \\
& $(3.863 \mathrm{e}-05)^{\star *}$ & $(7.818 \mathrm{e}-06)^{\star *}$ & $(2.375 \mathrm{e}-04)^{\star *}$ \\
Constant & 4.489 & -0.773 & 2.628 \\
& $(0.008)^{\star *}$ & $(0.002)^{\star \star}$ & $(0.037)^{\star *}$ \\
\hline
\end{tabular}

Columns (1), (2), and (3) are restricted to each answerer's first 10 answers, no matter how many answers that answerer ultimately answered. Columns (4), (5), and (6) consider all questions answered by answerers who retained experience $=10$ throughout the data. Columns (7), (8), and (9) consider all questions answered by answerers who reached experience $>10$ sometime during the data.

Table 7: Change in Answer Characteristics with Experience

\begin{tabular}{|c|c|c|c|c|c|c|}
\hline & (1) & (2) & (3) & (4) & (5) & (6) \\
\hline & Num & Num & Num & Answer & Answer & Answer \\
\hline & URLs & URLs & URLs & Length & Length & Length \\
\hline \multirow[t]{2}{*}{ Experience } & 0.004 & 0.102 & 0.039 & 1.589 & 92.960 & 130.033 \\
\hline & $(0.000)^{\star *}$ & $(0.039)^{\star *}$ & $(0.111)$ & $(0.275)^{\star *}$ & $(38.481)^{*}$ & (95.878) \\
\hline \multirow{2}{*}{ Constant } & 6.939 & 5.436 & 4.968 & $4,241.972$ & $3,117.439$ & $2,865.02$ \\
\hline & $(0.104)^{\star \star}$ & $(0.211)^{\star *}$ & $(0.350)^{\star *}$ & $(57.751)^{\star \star}$ & $(206.199)^{\star \star}$ & $(301.982)^{\star \star}$ \\
\hline Observations & 24290 & 3970 & 978 & 24290 & 3970 & 978 \\
\hline
\end{tabular}

Columns (1) and (4) consider all answered questions. Columns (2) and (5) consider all answered questions for which contemporary answerer experience was $=10$. Columns (3) 
and (6) consider all answered questions for which ultimate answerer experience remained $=10$.

Table 8: Hourly Pay and Experience

\begin{tabular}{|c|c|c|c|c|c|c|}
\hline & (1) & (2) & (3) & (4) & (5) & (6) \\
\hline & $\begin{array}{l}\text { Pay Per } \\
\text { Minute }\end{array}$ & $\begin{array}{l}\text { Pay Per } \\
\text { Minute }\end{array}$ & $\begin{array}{l}\text { Pay Per } \\
\text { Minute }\end{array}$ & $\begin{array}{l}\text { Pay Per } \\
\text { Minute }\end{array}$ & $\begin{array}{l}\text { Pay Per } \\
\text { Minute }\end{array}$ & $\begin{array}{l}\text { Pay Per } \\
\text { Minute }\end{array}$ \\
\hline Experience & $\begin{array}{r}4.394 \mathrm{e}-05 \\
(1.451 \mathrm{e}-05)^{\star *}\end{array}$ & & $\begin{array}{r}3.868 \mathrm{e}-05 \\
(1.452 \mathrm{e}-05)^{\star *}\end{array}$ & $\begin{array}{r}4.683 e-04 \\
(1.186 e-04)^{\star *}\end{array}$ & & $\begin{array}{r}4.287 e-04 \\
(1.190 e-04)^{\star *}\end{array}$ \\
\hline Ans Length & & $\begin{array}{r}1.649 \mathrm{e}-06 \\
(4.007 e-07)^{\star \star}\end{array}$ & $\begin{array}{r}1.641 \mathrm{e}-06 \\
(4.006 \mathrm{e}-07)^{\star \star}\end{array}$ & & $\begin{array}{r}2.371 \mathrm{e}-06 \\
(6.415 \mathrm{e}-07)^{\star \star}\end{array}$ & $\begin{array}{r}2.283 e-06 \\
(6.417 e-07)^{\star *}\end{array}$ \\
\hline Num URLs & & $\begin{array}{r}6.173 \mathrm{e}-04 \\
(2.231 \mathrm{e}-04)^{\star *}\end{array}$ & $\begin{array}{r}5.910 \mathrm{e}-04 \\
(2.233 \mathrm{e}-04)^{\star *}\end{array}$ & & $\begin{array}{r}2.147 \mathrm{e}-04 \\
(3.404 \mathrm{e}-04)\end{array}$ & $\begin{array}{r}1.570 \mathrm{e}-04 \\
(3.406 \mathrm{e}-04)\end{array}$ \\
\hline Constant & $\begin{array}{r}0.143 \\
(0.003)^{\star *}\end{array}$ & $\begin{array}{r}0.137 \\
(0.003)^{\star *}\end{array}$ & $\begin{array}{r}0.132 \\
(0.003)^{\star *}\end{array}$ & $\begin{array}{r}0.127 \\
(0.005)^{\star *}\end{array}$ & $\begin{array}{r}0.132 \\
(0.004)^{* *}\end{array}$ & $\begin{array}{r}0.118 \\
(0.006)^{\star *}\end{array}$ \\
\hline Observations & 24098 & 24098 & 24098 & 14483 & 14483 & 14483 \\
\hline
\end{tabular}

Columns (1) through (3) consider all answered questions, while (4) through (6) consider only those answered questions for which the answerer, at the time of answering the question, had experience $=100$.

\section{Table 9: Change in Specialization with Experience}

\begin{tabular}{lrr}
\hline & \multicolumn{1}{l}{ (1) } & \multicolumn{1}{l}{$(2)$} \\
& \multicolumn{1}{l}{ Specialization: } & \multicolumn{2}{l}{ Specialization: } \\
1-digit & 2-digit \\
Experience & $3.64 \mathrm{E}-03$ & $2.55 \mathrm{E}-03$ \\
& $(5.711 \mathrm{e}-04)^{\star *}$ & $(5.476 \mathrm{e}-04)^{\star *}$ \\
Constant & 2.037 & 4.83 \\
& $(0.030)^{\star *}$ & $(0.028)^{\star *}$ \\
\hline
\end{tabular}

Results consider only those answered questions for which the answerer, at the time of answering the question, had experience $=100$.

Table 10: Change in Ratings with Specialization

\begin{tabular}{|c|c|c|c|c|}
\hline & (1) & (2) & (3) & (4) \\
\hline & Rescaled & logit: & Gratuity & logit: \\
\hline & Rating & Rating = 4 & & Gratuity > 0 \\
\hline \multirow[t]{2}{*}{ Specialization } & 6.83E-03 & 1.33E-01 & 1.93E-01 & 8.44E-02 \\
\hline & $(1.415 e-03)^{\star \star}$ & $(2.882 e-02)^{\star \star}$ & $(3.845 e-02)^{\star *}$ & $(1.821 e-02)^{\star \star}$ \\
\hline \multirow[t]{2}{*}{ Experience } & 2.15E-04 & 2.86E-03 & 1.27E-02 & 7.30E-03 \\
\hline & $(8.484 e-05)^{*}$ & $(1.60 \mathrm{E}-03)$ & $(2.269 e-03)^{\star *}$ & $(1.092 e-03)^{\star *}$ \\
\hline \multirow[t]{2}{*}{ Constant } & -0.794 & 2.328 & 0.193 & -2.417 \\
\hline & $(0.005)^{\star *}$ & $(0.096)^{\star \star}$ & $(0.141)$ & $(0.072)^{\star *}$ \\
\hline
\end{tabular}


Results consider only those answered questions for which the answerer, at the time of answering the question, had experience $=100$.

Table 11: Specialization and Pay Per Minute, Average Question Price

\begin{tabular}{|c|c|c|c|c|}
\hline & (1) & (2) & (3) & (4) \\
\hline & Pay Per & Pay Per & Question & Question \\
\hline & Minute & Minute & Price & Price \\
\hline \multirow[t]{2}{*}{ Specialization } & $-7.514 \mathrm{e}-03$ & $-7.194 \mathrm{e}-03$ & $-4.044 \mathrm{e}-01$ & $-4.435 e-01$ \\
\hline & $(1.032 e-03)^{\star *}$ & $(1.072 e-03)^{\star \star}$ & $(8.497 e-02)^{\star *}$ & $(8.824 e-02)^{\star *}$ \\
\hline \multirow[t]{2}{*}{ Experience } & & $1.668 \mathrm{e}-05$ & & $-2.038 \mathrm{e}-03$ \\
\hline & & $(1.505 e-05)$ & & $(1.239 e-03)$ \\
\hline \multirow[t]{2}{*}{ Constant } & 0.170 & 0.167 & 20.014 & 20.392 \\
\hline & $(0.004)^{* *}$ & $(0.005)^{\star \star}$ & $(0.307)^{\star \star}$ & $(0.383)^{\star *}$ \\
\hline
\end{tabular}

Table 12: Summary Statistics by Day of Week

\begin{tabular}{lrrr}
\hline \multicolumn{1}{c}{ Day } & Avg Wage / Minute & Avg Time Diff & \# Qs Asked \\
Sunday & 0.1351 & 2031.62 & 5259 \\
Monday & 0.1632 & 2361.65 & 6806 \\
Tuesday & 0.1536 & 2072.81 & 7030 \\
Wednesday & 0.1526 & 2237.70 & 6963 \\
Thursday & 0.1480 & 2198.25 & 6696 \\
Friday & 0.1443 & 2533.73 & 5808 \\
Saturday & 0.1442 & 2026.29 & 4699 \\
\hline
\end{tabular}

Table 13: Compensating Differentials by Day of Week

\begin{tabular}{|c|c|c|c|c|}
\hline & (1) & (2) & (3) & (4) \\
\hline & Pay / Minute & Pay / Minute & Pay / Minute & Pay / Minute \\
\hline \multirow[t]{2}{*}{ Is Sunday } & $-1.63 E-02$ & $-1.64 \mathrm{E}-02$ & & \\
\hline & $(7.516 e-03)^{*}$ & $(1.93 E-02)$ & & \\
\hline \multirow[t]{2}{*}{ Interact Exper>10 \& Sunday } & & $-4.83 E-04$ & & \\
\hline & & $(2.10 \mathrm{E}-02)$ & & \\
\hline \multirow[t]{2}{*}{ Is Monday } & & & $1.61 \mathrm{E}-02$ & $-2.14 \mathrm{E}-02$ \\
\hline & & & $(6.598 e-03)^{*}$ & $(1.72 E-02)$ \\
\hline \multirow[t]{2}{*}{ Interact Exper $>10$ \& Monday } & & & & 4.31E-02 \\
\hline & & & & $(1.861 \mathrm{e}-02)^{*}$ \\
\hline \multirow[t]{2}{*}{ Experience $>10$} & & $3.44 \mathrm{E}-02$ & & 2.79E-02 \\
\hline & & $(6.786 e-03)^{\star *}$ & & $(6.916 e-03)^{\star *}$ \\
\hline \multirow[t]{2}{*}{ Constant } & 0.151 & 0.122 & 0.147 & 0.124 \\
\hline & $(0.003)^{\star \star}$ & $(0.006)^{\star *}$ & $(0.003)^{\star *}$ & $(0.006)^{\star *}$ \\
\hline
\end{tabular}


Table 14: Compensating Differentials during the Business Day

\begin{tabular}{lrrr}
\hline & \multicolumn{1}{l}{$(1)$} & \multicolumn{1}{l}{$(2)$} & \multicolumn{1}{l}{ (3) } \\
& Pay / Minute & Pay / Minute & \multicolumn{1}{l}{ Pay / Minute } \\
Business Day & $1.40 \mathrm{E}-02$ & $1.43 \mathrm{E}-02$ & $1.38 \mathrm{E}-02$ \\
& $(4.866 \mathrm{e}-03)^{\star \star}$ & $(4.866 \mathrm{e}-03)^{\star \star}$ & $(6.234 \mathrm{e}-03)^{\star}$ \\
Experience & & $4.48 \mathrm{E}-05$ & $4.34 \mathrm{E}-05$ \\
& & $(1.451 \mathrm{e}-05)^{\star \star}$ & $(1.833 \mathrm{e}-05)^{\star}$ \\
Interact Business Day - Experience & & & $3.83 \mathrm{E}-06$ \\
& & & $(3.00 \mathrm{E}-05)$ \\
Constant & & & 0.138 \\
& $(0.003)^{\star *}$ & $(0.004)^{\star \star}$ & $(0.004)^{\star \star}$ \\
\hline
\end{tabular}

Table 15: Business Day Answers and Experience

\begin{tabular}{lr}
\hline & Business Day \\
Experience & $-2.58 \mathrm{E}-04$ \\
& $(8.125 \mathrm{e}-05)^{\star \star}$ \\
Constant & -0.413 \\
& $(0.017)^{\star \star}$ \\
\hline
\end{tabular}

